\title{
MENCIPTAKAN GENERASI YANG BIJAK DALAM PENGGUNAAN MEDIA SOSIAL
}

\author{
Yesi Weningsari \\ Universitas Islam Indonesia \\ yesiweningsari@gmail.com
}

\begin{abstract}
Times will quickly change as the culture development. Indonesia is famous for its plurality, with various colors ranging from regional origin, language, tradition, and no less importance of belief. The beauty of Indonesia creates attraction for foreigners, so many come to explore just to learn Indonesian culture. Culture language is derived from Sanskrit buddhayah from the word of mind means the mind or reason, got the sense by Koentjaraningrat said that culture is the power of creativity, intention, and taste, when added the prefix "to" and the end "an" got the word culture has the meaning of behavior or community behavior that is mutually agreed upon in living the rules of life (Srihadi \& Srimuryati:2013:p.102). Teenagers become one of the drivers of the changing times, someone who says teenagers if they have undergone physical changes or attitudes. Someone who was categorized as a teenager when he reached the age of 16,17, up to 18 years. Behavior change in adolescents is often referred to as stereotypes that lead to more negative influences, such as self-destructive behavior or imitating poor performing styles on idol artists, this is a barrier between parent-child relationships so the problem of the child is difficult to solve itself (Hurlock: 1980) Human life runs socially to meet the needs of everyday life, if there are people who think that he can live because of his own efforts it is very impossible, even we live in the forest still need other creatures. Interactions that occur between people per person can be done in various ways one of them communication. Communication can be done directly or through media or intermediary. Media is a tool used in conveying messages, while there is an addition of NEA (National Education Assiciation) that forms print, audio-visual, and various other communication (Sanaky H.AH.: 2013). If media and social are combined then it will gain a
\end{abstract}


new understanding of social media. Social media can also be said as an online medium in which people want to use the need to create a profile and login first, the positive impact that there are many, become the main thing is to facilitate communication, can know various information, share photos or video, and make various places specifically to train skills such as blogs or wikipedia (Center of Public Relations Ministry of Trade, 2014).

Keywords: Culture, Teenagers, Social media

\section{Pendahuluan}

Kemajuan zaman memberikan dampak yang cukup berarti bagi kehidupan, kemudahan banyak ditemui semenjak manusia mengenal teknologi informasi dan komunikasi. Media sosial menjadi salah satu contoh alat yang muncul akibat perubahan zaman, tujuan umumnya sebagai alat penghubungan antar orang per orang, sedangkan secara khusus terletak pada diri setiap individu, bisa dijadikan tempat penjualan atau dikenal dengan istilah online shop, kemudian mengenali identitas diri lewat hobi, seperti menulis, fotografer atau modeling, kegiatan-kegiatan tersebut tentu bermanfaat, akan tetapi jika sudah keluar dari koridor, yang sebenarnya akan merugikan, itulah yang akan menjadi bumerang bagi diri sendiri, perubahan sikap yang akan terjadi, serta lingkungan menjadi kena dampaknya.

Dunia maya menjadi dunia yang tanpa ukuran batas ruang dan waktu, jika warga internet, atau lebih dikenal dengan istilah netizen tidak sadar dengan waktu yang terbuang. Perkembangan zaman yang semakin maju berkaitan erat dengan modernisasi dan westarnisasi, sedangkan kedua istilah tersebut berhubungan dengan budaya. Lama-kelamaan Indonesia akan mengalami hal yang sama soal kebebasan, yang dipegang dari hak setiap individu, lalu melunturkan rasa kepedulian. Sifat-sifat individulis yang akan lahir, serta tertanam menjadi akar.

Pemanfaatan Ilmu Pengetahuaan Teknologi dan Informasi (IPTEK) yang berupa media sosial salah satunya, perlu kehati-hatian dengan keseimbangan yang dibarengi moral, jika tidak demikian, 
anak-anak dibawah umur, yang kurang perhatian dari orangtua, dapat dengan mudah mengakses segala macam hal diluar batas nilai atau norma bangsa Indonesia. Media sosial menjadi jenis segala macam sarang keuntungan bagi yang menikmati dengan menggunakan nafsu, tidak seimbang melalui akal fikiran (rasional). Media sosial menjadi perantara antar satu individu ke individu lain, individu ke kelompok, kemudian kelompok ke kelompok untuk melakukan interaksi sosial di dalamnya, sehingga terdapat dua kacamata sisi dari media sosial.

Media sosial merupakan dua kata dari masing-masing makna yang berbeda, diantara media dan sosial. Menurut laughey (2007) dan McQuail (2003) bahwa media merupakan alat perantara menghubungkan komunikasi, sedangkan sosial ialah peran yang dilakukan setiap individu dengan memberikan arti lebih di lingkungan masyarakat (Mulawarman dan Aldila Dyas Nurfitri, 2017:37). Media sosial pada kenyataannya tidak melulu sama dengan realita, seringkali manusia juga menipu lewat media, melalui berbagai macam informasi yang disebarkan, tidak sesuai dengan fakta di lapangan yang terjadi. Kesimpulan pemaknaan media sosial berarti aktivitas yang dilakukan oleh manusia yang dapat menimbulkan efek di lingkungan sosial, baik itu berpengaruh baik juga dapat buruk.

ABG kepanjangan Anak Baru Gede, biasanya usianya dapat dikategorikan masih remaja, sangat mudah media mempengaruhi mereka, bahkan kegagalan pada akhirnya bersandar jika terbawa arus negatif. Pengertian dari remaja, menurut Badan Kesehatan Dunia (WHO), dapat dimaknai dari tiga aspek kehidupan yaitu, biologis, psikologis, dan sosial ekonomi. Segi biologis dapat melihat dari pertumbuhan fisiknya sampai mencapai pubertas atau kematangan seksual, kemudian dari sisi psikologis ialah tidak terlihat atau non fisik, misalnya berupa perilaku untuk mengenali jati dirinya, terakhir sosial ekonomi, merupakan usaha remaja yang dilakukan dalam aspek ekonomi supaya tidak membebani kedua orangtua, atau berusaha memenuhi kebutuhan hidup sendiri S.Wiraman (2002) dalam Khamim Zarkasih Putro, (2017:25).

Anak menjadi penerus yang akan memegang tanggung jawab dalam setiap peranan tugas di massa depan, atau acap kali kita sering 
menyebutnya sebagai penerus generasi di massa mendatang. Generasi secara umum dimaknai sebagai keadaan seseorang yang seumuran usianya, sedangkan secara emplisit lebih kepada usia kelahiran sampai massa mendekati dewasa, sehingga mereka sudah mampu memenuhi kebutuhan diri sendiri, pemaknaan ini dirangkum dari pendapat beberapa tokoh (Muzakkir,2015:114). Zaman akan berubah, maka sudah seharusnya meninggalkan jejak yang dapat dimanfaatkan bagi anak cucu, selain itu warisan budaya serta moral adat istiadat perlu menjadi akar identitas anak muda, supaya tidak mudah goyah dengan arus zaman.

\section{Pembahasan}

\section{Pemfilteran Media Sosial}

Hoaks atau berita bohong mudah tersebar lewat media sosial, sehingga mempengaruhi tingkah laku remaja dalam sehari-hari, baik itu kepada diri sendiri, ataupun perubahan orang-orang di lingkungan sekitar. Pemfilteran ialah upaya remaja atau anak-anak ketika menghadapi informasi yang diperoleh dari media sosial, juga bisa dunia maya atau internet, dapatkah mereka mepilah-pilah mana hal baik dan buruk. Keadaan yang rawan terjadi di Indonesia yaitu, pada masalah tingkat literasi, kategori masih rendah, sehingga ketika memperoleh informasi biasanya langsung disebarkan begitu saja, tanpa dicek terlebih dahulu sumber kebenaran dari informasi, apakah sudah berasal dari sumber berita yang terpercaya. Proses menyebarkan informasi juga mengalami kerugian, boleh jadi apa yang disebar tidak melihat pada nilai-nilai atau norma budaya bangsa Indonesia, tidak sedikit orang yang tergoda dengan hal-hal yang menimbulkan syahwat, misal konten video pornografi, bahkan sampai dapat mengalami ketagihan (Roswita Oktavianti dan Riris Loisa, 2017: 88).

Pengaturan waktu penggunaan handphone atau gadzet dalam sehari-hari tentu perlu menjadi perhatian khusus, terutama bagi orangtua dan guru. Guru mempuyai tanggung jawab dalam dunia pendidikan, dimana dihadapkan pada siswa yang usianya ratarata masih anak-anak atau remaja, pepatah Jawa mengatakan guru akronim dari "digugu lan ditiru", maka setiap tindak tanduk seorang 
guru lebih diutamakan, sebab anak akan mencontohn ya. Sikap seorang guru haruslah ramah pada anak murid, jika ternyata ada beberapa penyimpangan da ri tingkah laku anak, maka pendekatan yang dilakukan oleh guru perlu tepat sasaran, akibatnya tidak menyebabkan si siswa merasa tertekan, guru profesional ialah guru yang mempunyai tanggung jawab dalam kepribadian sikap, spiritual, intelektual, sosial, dan moral, serta spiritual (Ibdalsyah, Muhayani dan Deni Zaini Mukhlis, 2019: 405).

Pemandangan tidak langka jika melihat anak muda saat ini berjamjam sekedar menunduk, mengotak-atik HP digenggamannya. Ungkapan menjauhkan yang dekat dan mendekatkan yang jauh, menjadi dua sisi kaca $\mathrm{m}$ ata yang berbeda, seketika menjauhkan yang dekat, pernah bahkan sering jika seorang anak atau antar teman saja, diajak bicara tidak langsung menanggapi, bahkan orangtua mungkin kualahan sampai-sampai melihat kondisi anak, hampir menghabiskan waktu di depan HP tanpa membantu perkerjaan di rumah. Mendekatkan yang jauh menjadi hal positif, sehingga yang semula belum kenal, menjadi kenal bahkan bisa berinteraksi satu sama lain.

Kesadaran perlu dibentuk dari dalam diri sendiri, yang mungkin dimulai dari pembiasaan sehari-hari. Misalnya berupa hobi positif, masih usia anak-anak sebagai orangtua seharusnya mengetahui apa yang menjadi mayoritas kegiatan positif yang anak suka, supaya tidak termakan waktu anak, untuk dihabiskan sekedar bermain gadzet, dampak negatif juga kesulitan berinteraksi sosial antar teman sebaya, bahkan bisa sampai usia dewasa di masyarakat. Anak akan lebih individualis, rasa egoisnya tinggi mementingkan diri sendiri, tanpa peduli oranglain. Dampak positifnya juga banyak dirasakan lewat media sosial, kemudahan yang dirasakan terutama, akibatnya warga negara Indonesia lebih konsumtif, karena apapun dapat dengan mudah dipesan lewat gadzet atau $H P$, sehingga tidak usah repot-repot pergi jauh-jauh keluar rumah, mencari sesuatu yang menjadi keinginannya.

\section{Moral dan Rasa Integrasi}

Moral berkaitan dengan etika dalam hal bertingkah laku, dalam pendidikan Islam sendiri lebih dikenal dengan istilah akhlak. 
Pengertian moral berasal dari dari bahasa Yunani ialah mores, artinya berupa pembiasaan atau adat kebiasaan, secara bahasa Indonesia moral berarti asusila. Moral secara istilah dapat bermakna, suatu tindakan manusia yang mencerminkan hal baik, tidak keluar jauh dari nilai-nilai atau norma (Ilham Hudi, 2017: 31-32). Moral anak paling besar dipengaruhi oleh lingkungan, mulai kelompok bermainnya di rumah, sampai dari sesuatu yang belum kita ketahui sebagai orang tua, seringkali anak tidak diperhatikan, yaitu komunikasi interaksi anak lewat jejaring dunia maya. Dampak yang terjadi cukup besar, misalnya sampai kejadiaan seorang anak hamil di luar pernikahan, atau memperkosa temannya satu kelas. Keseimbangan dari moral terletak pada didikan orang tua selama di rumah, yang dibarengi dengan nilai-nilai agama.

Moral bangsa Indonesia yang bersumber pada landasan dasar negara yaitu, pancasila. Pembelajaran dari nilai-nilai setiap sila pancasila tersebut seolah sekedar cukup dibacakan saat upacara bendera berlangsung, soal praktik yang dilakukan sehari-hari kurang menjadi perhatian bagi guru ataupun orang tua, misalnya anak masih ada saja yang berkelahi, bisa dicerminkan sikap persatuan atau integrasi Indonesia masih lemah, lalu anak masih ada yang berkata kotor, boleh jadi anak belum memaknai kandungan ketuhanan Yang Maha Esa. Miris juga ketika mengetahui beberapa anak sampai tidak hafal lagu-lagu kebangsaan, kondisi semacam inilah yang akan menjadi masalah bagi generasi di massa mendatang.

Rasa apatis mulai dihinggapi anak, bermula dari sikap individualis. Tutup mulut rapat-rapat, seolah dalam peribahasanya, anak tak mudah mempunyai rasa untuk berbagi, rasa egoisnya tinggi, hingga menghilangkan rasa empati. Komunikasi akan semakin berkurang antar anggota keluarga, begitulah gambaran dari apatis, anak akan mengalami kesulitan dalam beinteraksi sosial, fenomena yang tidak langka, biasanya anak akan mengunci diri di kamar entah apa saja yang Ia lakukan, hanya berkutat di kamar. Bekal anak yang sesungguhnya padahal akan belajar bagaiamana interaksi sosial, melalui cara melatih komunikasi yang baik, sebagaimana nanti-nantinya Ia akan terjun di lingkungan masyarakat. 
Masalah remaja lebih tinggi pada keadaan tingkat emosi, sehingga banyak yang merasa tertekan dengan kondisi tertentu, penyebabnya karena situasi sosial yang sulit dimengerti oleh mereka, yang seolah menuntut mereka untuk melakukan suatu hal yang terkadang tidak sesuai dengan kemauannya, tetapi tetap Ia menjalankan, tetapi tidak menutup kemunkingan setiap hal yang tidak sesuai dengan kemauannya tidak baik untuk mereka. Pendapat tokoh yang bernama Gesell bahwa, remaja yang berkisar umur 14 tahun amarahnya atau saat emosi mudah terangsang, bahkan akan meledak, sehingga dalma diri si anak tidak mudah mengendalikan dengan sendirinya. Umur sekitar 16 tahun perasaan tertekannya akan berkurang, saampai mendekati usia dewasa. Tindakan luapan emosi seorang remaja sering dilakukan dengan berdiam, bukan teriak-teriak, melainkan dengan sekedar menggerutu, kemudian rasa iri hatinya tinggi jika temannya mendapatkan kebahagiaan, serta mempunyai inisiatif untuk mendapatkan pekerjaan, meskipun sampai akhirnya menginginkan berhenti sekolah untuk mendapatkan pekerjaan kutipan dari buku Elizabeth B. Hurlock (1980) dalam terjemahan Istiwidayanti dan Soedjarwo (2017) : 212-213.

\section{Kontribusi Anak Muda}

Perkembangan zaman cukup akan berubah dimulai dari para pemuda, jika pemuda dapat mengetahui dengan sendirinya, atau perantara oranglain, peran apa yang perlu Ia mainkan. Berbeda jika pergerakan mereka sadari sendiri, bermula dari hobi misalnya, kemudian mendapat keuntungan lalu dapat berbagi, bukan saja soal material, tetapi memberikan inspirasi saja sudah menjadi hal yang sangat berkontribusi bagi orang lain. Anak muda atau remaja masih perlu arahan dalam setiap bimbingan dalam aktivitas kesehariannya, apakah hal tersebut menguntungkan, atau bahkan berdampak buruk.

Anakmuda sudah seharusnya dilatih untukmemilikikemandirian, seusianyasudahmampuuntukmempunyainalar, bahwamenginginkan sesuatu itu tidaklah mudah, sekedar meminta terus-terusan dari orang tua. Orangtua perlu mengenali anaknya, dengan beberapa hal dari perubahan kondisi fisik dan pengaruhnya bagi dirinya, suasana psikis 
si anak, menjadi orang tua yang hangat untuk mendengarkan cerita anak hingga akhirnya berbagi cerita, masalah seksual yang diperoleh dari berbagai macam sumber, serta perubahan sosial mulai dari life style yang dipengaruhi media sosial dan lingkungan bermain. Lingkungan keluarga, sekolah, dan masyarakat mempunyai hubungan yang harusnya saling berkontribusi, memberikan kondisi yang membuat remaja dapat tumbuh lebih kreatif, serta tidak bermalas-malasan. Misalnya salah satunya di lingkungan masyarakat, para pemuda yang sekumpulan dari anak muda atau remaja, diberikan tanggung jawab mengikuti berbagai macam kelembagaan di masyarakat, mulai karang taruna, RISMA dan KNPI (Ali Rahman, 2016: 30-31).

Kontribusi anak muda dari media sosial, misal sesuai dengan hoby mereka, anak remaja tersebut suka pada bidang fotografi, maka akan mengumpulkan foto-foto untuk kemudian di upload, sehingga menimbulkan ketertarikan dari dunia luar yang berbisnis tentang fotografer, akhirnya anak dipanggil dan mendapatkan penghasilan. Usaha yang dilakukan melalui media sosial, kemudian sebagian keuntungan anak lakukan untuk berbagi kepada orang-orang yang sedang mengalami kesulitan. Akibatnya jika setiap anak muda dapat sadar untuk memanfaatkan media sosial sebagai alat perantara pekerjaan, maka akan terkumpul banyak anak muda yang turut berkontribusi dalam kemajuan bangsa.

\section{Kesimpulan}

Berdasakan pembahasan dapat diambil kesimpulan ada tiga point penting, yang pertama soal pemfilteran media sosial, kedua moral dan rasa integrasi, terakhir kontribusi anak muda. Pemfilteran media sosial mempunyai arti bahwa, anak muda perlu dapat membedakan mana informasi yang baik dan buruk untuk yang dapat dibutuhkan, kemudian moral, berkaitan dengan sikap atau tingkah laku dalam keseharian, sedangkan rasa integrasi yaitu rasa persatuan kesatuan, sehingga hal ini dapat berhubungan kuat dengan sifat toleransi. Terakhir kontribusi anak muda, mempunyai makna apa yang dilakukan anak muda, sehingga dapat memberikan pengaruh bagi orang lain, entah dari media sosial atau pun langsung dunia 
nyata di lingkungannya. Beberapa langkah yang dapat dilakukan guna memanfaatkan media sosial secara bijak, dari hasil penelitian Fahmi Anwar mahasiswa dari Kalbis Institute Jakarta, jurusan Ilmu Komunikasi yaitu, cek kebenarasan sumber informasi supaya tidak terjebak pada penyebaran berita hoaks, menggunakan etika dalam hal komunikasi, misalnya bahasa yang digunakan sopan, hindari berita yang mengandung sara serta pornografi, lalu ketika mendapati hasil karya orang lain maka jadilah hal tersebut sebagai inspirasi, terakhir berhati-hati dalam berbagi informasi pribadi, misal mulai foto diri, perlu menjadi kehati-hatian ( Fahmi Anwar, 2017: 142).

\section{Daftar Pustaka}

Anwar F.,2017. Perubahan dan Permasalah Media Sosial. Jurnal Muara Ilmu Sosial, Humaniora, dan Seni. Vol.1. No. 1 Juni. https://journal.untar.ac.id/index.php/jmishumsen/article/ download/343/284

Elizabeth B. Hurlock B.E., (1980) dalam terjemahan Istiwidayanti dan Soedjarwo (2017). Development Psychology A Life-Span Approach, Fifth Edition diterjemahan berjudul Psikologi Perkembangan suatu Pendekatan Sepanjang Rentang Kehidupan. Edisi ke lima. PT Penerbit Erlangga.

Hudi I.,2017. Pengaruh Pengetahuan Moral terhadap Perilaku Moral pada Siswa SMP Negeri Kota Pekan Baru berdasarkan Pendidikan Orangtua. Jurnal MoralKemasyarakatan,Vol.02.No.01.Juni. http://ejournal.unikama.ac.id/index.php/JMK

Ibrahim M. M., Tinus A., \& Rahmandani F. 2018. Analisis Dampak Penggunaan Gadzet (Smartphone) Terhadap Kepribadian dan Karakter (KEKAR) Peserta Didik di SMA Negeri 9 Malang. Jurnal Civic Hukum, Vol. 3. No. 1. http:/ejournal.umm.ac.id/index. $\mathrm{php} / \mathrm{jch}$

Loisa R.,\& Oktavianti R .2017. Penggunaan Media Sosial Sesuai Nilai Luhur Budaya di Kalangan Siswa SMA. Jurnal Pengabdian kepada Masyarakat (JPKM), Vol. 3. No. 1. September. http:// jurnal.ugm.ac.id/jpkm 


\section{eL-Tarbawj}

Muklis Z.D.,Muhyani., \& Ibdalsyah. 2019. Media Sosial dan Pengaruhnya terhadap Kesadaran Beragama sebagai Akibat dari Pola Asuh Orangtua dan Peran Guru di Sekolah. Edukasi Islami : Jurnal Pendidikan Islam, Vol. 08.No.02.Agustus.https://jurnal.staialhidayahbogor. ac.id/index.php/ei/article/download/538/412

Muzakkir. 2015. Generasi Muda dan Tantangan Abad Modern serta Tanggung Jawab Pembinaannya. Jurnal Al-Ta'dib. Vol. 8. No.2. Juli-Desember. https://media.neliti.com/media/ publications/235781-generasi-muda-dan-tantangan-abadmodern-e0361826.pdf

Nurfitri, D.A, dan Mulawarman. 2017. Perilaku Pengguna Media Sosial berserta Implikasinya Ditinjau dari Prespektif Psikologi Sosial Terapan. https://jurnal.ugm.ac.id/buletinpsikologi

Putro, Z.K. 2017. Memahami Ciri dan Tugas Perkembangan Masa Remaja. APLIKASIA (Jurnal Aplikasi Ilmu-ilmu Agama), Vol.17. No.1. page 25-32. ONLINE: ejournal.uin-suka.ac.id./pusat/aplikasia

Rahman A.,2016. Pengaruh Negatif Era Teknologi Informasi dan Komunikasi pada Remaja (Perspektif Pendidikan Islam). Jurnal AlIshlah, Januari-Juni. http://ejurnal.iainpare.ac.id/index.php/ alislah/article/view/384/294

Supratman P.L.,2018. Penggunaan Media Sosial oleh Digital Native. Jurnal Ilmu Komunikasi,Vol.15.No.1.Juni.https://ojs.uajy.ac.id/ index.php/jik/article/download/1243/1152 